\title{
Verification of PBL Activation Methodologies by the SECI Model in Entrepreneurship Education Program
} - The VIA Model for Fostering the Preliminaries of Entrepreneurial Intentions -

\author{
Koichi TAKAHASHI and Masahiro KIYOSUMI
}

\author{
Graduate School of Integrated Frontier Science, Kyushu University, Fukuoka 815-0032, Japan
}

\begin{abstract}
Entrepreneurship education programs in universities are flourishing. The programs in Europe provide practical knowledge and skills on top of learning an entrepreneurial attitude. On the other hand, in the U.S., programs just provide practical knowledge and skills. In Japan, the programs provide practical knowledge and skills in the US style. However, it is very unlikely that students who will launch their business immediately after completing the program. In order to actually start a business, it is essential to develop "Entrepreneurial intentions," but all program participants do not necessarily foster entrepreneurial intentions. In this paper, we define the preliminaries of entrepreneurial intentions as the willingness of students participating in the program to actively engage in PBL activities. As a means of fostering the preliminaries of entrepreneurship intentions, a series of methodologies is proposed as the VIA model using the SECI model's conceptual framework as a means to verify its effectiveness.
\end{abstract}

Keywords: VIA model, SECI model, Entrepreneurship education program

\section{INTRODUCTION}

University entrepreneurship programs are adopting Silicon Valley-style methodologies such as the Lean Launch Pad. A typical entrepreneurship program begins with the ideation method. The ideation method focuses on the quality of the issue and designs expected customer usage scenes called customer journeys by assuming "personas" of users who use the product or service. This method is very useful for thinking about business model. On the other hand, it is generally assumed that aspiring entrepreneurs have some kind of purpose or motivation, such as money or success; Kwong et al. [1] noted that student entrepreneurs need to elicit enthusiasm while gaining experience and knowledge for the start-up.

The OECD (2009) report states that entrepreneurship education needs to be divided into objectives, such as whether to develop entrepreneurial attitudes or practical knowledge and skills for starting a business. They refer to the former as Softer outcomes (entrepreneurial attitude) and the latter as Hard outcomes (acquisition of practical knowledge and skills), referring to the importance of Softer outcomes.

Figure 1 shows the diagram of entrepreneurship education created by Takahashi [2]. The vertical axis is entrepreneurial activity and the horizontal axis is entrepreneurial attitude. Babson University, which is famous for its entrepreneurship education in the U.S., says that the purpose of the education is to move students at point B to point A, that is, to lead students with entrepreneurial attitudes to entrepreneurial activities. On the other hand, in European universities, the purpose of education is to move students from point $\mathrm{C}$ to point B. In other words, the purpose of education is to form an entrepreneurial attitude.

In Japan, the focus is on entrepreneurship education programs to move students from point $\mathrm{B}$ to point $\mathrm{A}$, which are modeled after Silicon Valley-style programs. Certainly, the dualistic categorization of entrepreneurial attitudes and entrepreneurial activities is easy to understand. However, it would be questionable to apply the educational program on "practical knowledge and skills" to undergraduate and graduate students who do not yet have "entrepreneurial attitudes", assuming that they already have them. If the university students do not have an "entrepreneurial attitude", will team-based project

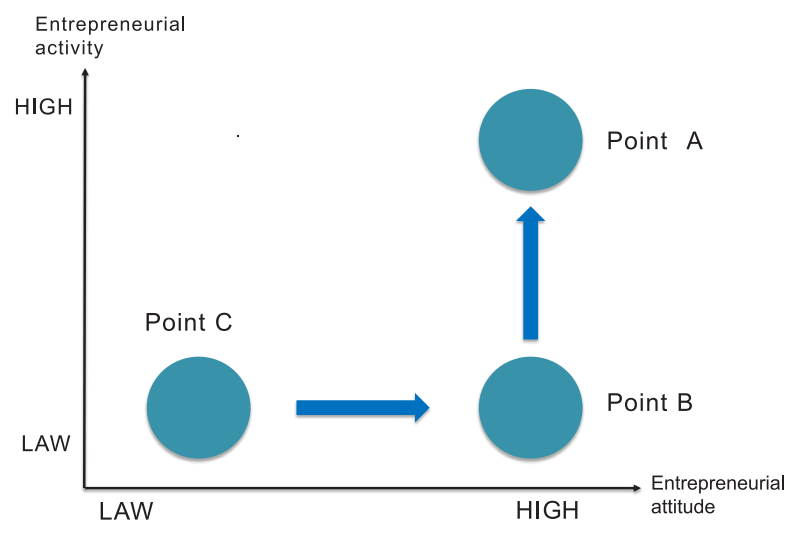

Figure 1: Two types of the entrepreneurship education programs (Noriyuki Takahashi 2013) 
such as PBL proceed smoothly? If the team members face various difficulties, do they continue to work together until the final debriefing day, called Demo Day? In addition, if undergraduate and graduate students do not have an entrepreneurial attitude, the question is whether they are equipped with the entrepreneurial education program in the first place, and if so, by what means?

Based on the importance of shared activity objectives and decision-making participation among team members in collaborative learning, this study focuses on entrepreneurship education program through PBL, and examines the development and effectiveness of the methodologies from self-awareness to team vision statement creation as a means of activating PBL.

Generally, the subject of the act of self-awareness has been adults. Undergraduate and graduate students who have no social experience are still in the process of establishing themselves. However, this study assumes that it is possible for undergraduate and graduate students to recognize the present sense of values. It is hypothesized that this methodology will allow university students to recognize their own sense of values and create a team vision statement while understanding and respecting each other, which is a "collaborative" process that will have a positive impact on subsequent PBL activities. The academic theory that supports this hypothesis is "the priming effect" in cognitive psychology. The priming effect is a cognitive psychology term that refers to the effect of giving specific stimulus in advance to a subsequent. It is the activation of information processing. The priming effect, in which the human behavior is changed by the idea, is called "the Ideomotor effect". In addition, this study will use "Socialization" of the SECI model as conceptual framework. According to Nonaka[3], Socialization is the process for creating tacit knowledge, such as mental models and skills by sharing mutual experiences among team members.

In this study, the importance of sharing the purpose of activities and participation in decision-making among team members in cooperative learning was taken into account in the study of entrepreneurship education program, and the participation in decision-making by team members in the early stages of PBL activities was reviewed within the framework of "Socialization" and "Externalization" in the SECI model. "Socialization" involves sharing sense of values of each individual with the team members that underlie decision-making. Next, "Externalization" codifies the team vision based on respect for sense of values of the team members. We have developed a concrete methodology called the VIA model

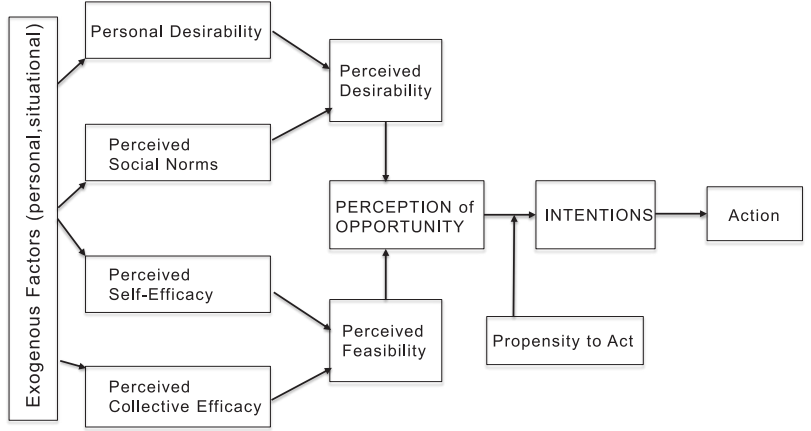

Figure 2: The entrepreneurial intentions model (Krueger, 2000; Krueger \& Brazeal, 1994; Krueger et al., 2000: Shapero, 1982)

by positioning the series of activity processes from "Socialization" to "Externalization" of the SECI model as an PBL activation model, and have incorporated it into the cooperative learning of PBL to verify its effectiveness.

The Theory of Planned Behavior (TPB) is the standard theory for designing entrepreneurial education program by Ajzen [4], who shows that the first step when a person acts is "intention", which is influenced by the "attitude", "subjective norms" and "perceived behavioral control" of the person acting. According to Ajzen, it drives action, and Figure 2 shows The Entrepreneurial Intentions Model by Krueger \& Day [5] which is a progressive theory based on the TPB. The Entrepreneurial Intentions Model is structured as follows. There are four key elements: "individual desire," "social norms," "self-efficacy," and "collective efficacy. It is hypothesized that these factors will influence a strong intention to set up a business. Although there had been the standard theoretical research such as TPB and The Entrepreneurial Intentions Model, there were lack of specific theories of methodologies to foster the entrepreneurial intentions.

The Entrepreneurial intentions model is a linear process. As Simon [6] views the human brain as a flow, like an information processing system, and the four elements of the Entrepreneurial intentions model are also factor-reductive. These two prior research models are based on the subject (person) and object (activity) dualism. It is true that people are influenced by external factors in their decision-making, but it is difficult to explain the process from decision-making to action in a flow diagram based on the dualism of subject and object, as the Entrepreneurial Intentions Model.

In this study, we have developed an approach to entrepreneurship education programs based on the "Socialization" of the SECI model of self-awareness as a starting point, based on the subject-object identity perspective of the SECI model, rather than the subject- 
object dualistic interpretation presented by previous studies of TPB and the entrepreneurial intentions model.

Sinek [7] states that when a leader starts a new business based on his values and beliefs, he starts with a "why," but then "intent" is to have some motivation. In other words, the personal definition of "meaning," which underlies "meaning," comes from personal values;

As March and Olsen [8] stated, the essence of human decision-making is ambiguity and irrationality, the humans do not act with an explicit awareness of these four elements. Rather, the four elements are presented as retrospective rationality that is explained in retrospect, as Weick [9] says. We recognize that these four important factors derive from individual sense of values. Tomano [10] states that value recognition is the recognition of one's intrinsic desires. Value perceptions are related to "personal desires" in the Entrepreneurial Intentions Model and are also related to "social norms" and "self-efficacy". The purpose of entrepreneurship education program is to produce entrepreneurs through the education program. Increasing entrepreneurial intentions certainly encourages entrepreneurial activity.

On the other hand, the number of university students who immediately start a business after completing the program is very limited. In other words, a three-month or six-month education program period is not enough time for university students to initiate actual entrepreneurial activity. It is difficult to say that this is sufficient in terms of cultivating entrepreneurial intentions. Therefore, it is important to note that the state in which entrepreneurial intentions are matured immediately after completing the entrepreneurship education program. It's not realistic to expect it. Therefore, we assume the process of building entrepreneurial intentions and call it the "The Preliminary stage of entrepreneurial intentions". "The Preliminary stage of entrepreneurial intentions" means that the intentions to start a business is not yet cultivated, but the interest in entrepreneurship is getting higher. It refers to the psychological state of wanting to actively engage in PBL activities. Through the entrepreneurship education program, "The Preliminary stage of entrepreneurial intentions" of university students was fostered. In this case, the expected effect is to keep the team motivated to engage in PBL activities until the end as a rehearsal for entrepreneurship. In this study, Intention of the VIA model means the pre-stage of entrepreneurial intentions. In other words, we define Intention as "increasing the willingness to accomplish PBL as a team" and The work that enhances the work will be developed as VIA model and its effect on subsequent PBL activities will be tested.

\section{THE VIA MODEL}

\subsection{The key concept of the methodologies}

There are two major key concepts in this study. One is that we have changed the view of entrepreneurial intentions in entrepreneurship education program. The traditional debate about whether entrepreneurial intentions are developed or not by entrepreneurship education programs is superficial and poorly developed.

It is not realistic to expect that university students are able to acquire entrepreneurial intentions immediately through the programs. Or rather, they will work together as a team to complete PBL activities as pre-stage to the entrepreneurial intentions. We considered what factors drove the engine of motivation. As a result, we developed a methodology from the perspective of fostering selfawareness.

In the VIA model, entrepreneurial intentions are fostered through the emotional, while there is a paucity of empirical research on motivation and other emotional changes as Nabi et al. [11] state, the framework of the SECI model use, and in "Socialization" begin by recognizing one's own values as the root of intrinsic motivation, and In "Externalization", tacit knowledge is transformed into formal knowledge through the creation of team vision statement. It has demonstrated that it can motivate people to engage in PBL activities in this study.

The second is the use of the concept of "identification of subject and object" which is common to the SECI model and sense-making. This study does not assume the dualism of subject (person) and object (activity) as in the TPB and entrepreneurial intention models of previous studies. In this study, the subject (students) became part of the object (activity) in the entrepreneurship education program, while the subject (students) became part of the object (activity), and through the PBL activity, the implications of the PBL activity gradually changed, and the values and motivation of the students are gradually formed as a cyclical model.

\subsection{The priming effect}

Figure 3 shows The VIA model, that is PBL activation process in entrepreneurial education based on the TPB and Entrepreneurial Intentions models." The "V" refers

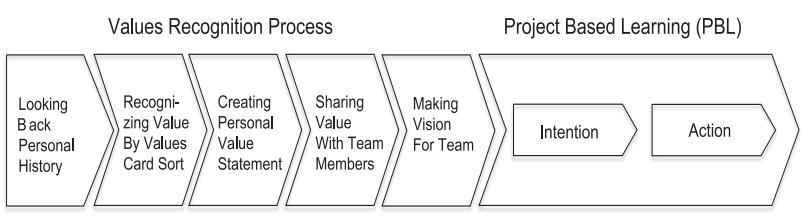

Figure 3: The value recognition process of the VIA model 
to the value recognition process that triggers Intention and triggers subsequent actions on the PBL." The "I" stands for Intention and the "A" for Action.

In addition, "VIA" means that PBL is activated through self-awareness. Intention and action follow the concepts of the TPB and the Intention Model, while the VIA model has a theoretical basis in the cognitive psychology concept of the priming effects. Kahneman [12] argues that the priming effect is the effect of providing a specific stimulus beforehand that subsequently activates information processing; the VIA model expects university students to recognize the sense of values, share it with team members, and create team vision statement with them; the measure of effectiveness of the VIA model is not the start-up of a new business, but the continuity of team activities in PBL.

\subsection{Leveraging the VIA model}

Figure 4 is The SECI model, a management theory that explains "the Knowledge creation process" invented by Nonaka, which is a concept that supports the VIA model.

Iriyama [13] says that at the root of the SECI model is the dynamic interaction of tacit and formal knowledge among individuals in an organization. We understand that entrepreneurship is one of "the Knowledge creation processes" to generate innovative business models, then, utilize the framework of the SECI model in our entrepreneurship education program. Furthermore, we refer to the phenomenology of the German philosopher Husserl as a philosophical and psychological concept corresponding to the SECI model. The main concepts of phenomenology are "subject-object identity" and "orientation". The mind-body dualism derived from Descartes states that the subject "observing" and the object "being analyzed" are separated. On the other hand, in phenomenology, "subject and object are the

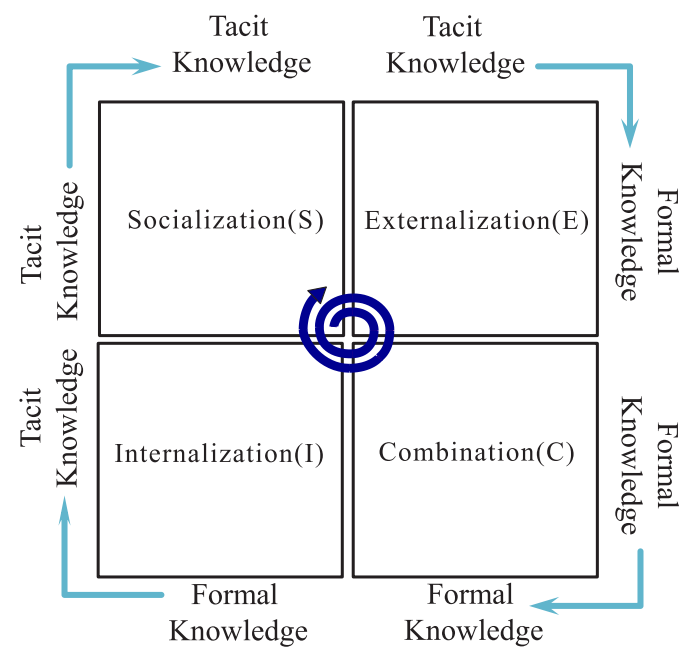

Figure 4: SECI model (Nonaka \& Takeuchi 1996) same", and the SECI model has a high affinity with the idea of self and others non-separation, which does not separate human beings from their environment, and Iriyama states that the SECI model has a high affinity with phenomenology. Instead of a dualistic interpretation, such as "entrepreneurial attitude" and "practical knowledge and skills", which are components of an entrepreneurship education program, if interpreted phenomenologically, it should be considered that both will be enhanced through the process of PBL activities, from the perspective of "the identity of entrepreneurial attitude as a subject and practical knowledge and skills as an object". In other words, it is an abduction that entrepreneurial attitudes and practical knowledge and skills are enhanced by sustained activities on the SECI model.

Figure 5 shows the relationship between the SECI model and the VIA model. "Socialization" is the recognition of one's own sense of values and a place to share them with team members. Next, "Externalization" creates team vision statement and fosters at the preliminary stage of entrepreneurial intentions.

In "Combination" and "Internalization," university students carry out PBL activities as a team. Through these activities, they will further deepen their awareness of their own values.

Table 1 compares the three concepts: the SECI model, Sense-making, and the VIA model. This table seems a process diagram, but it is a circular cycle rather than a linear one. Socialization of the SECI Model and

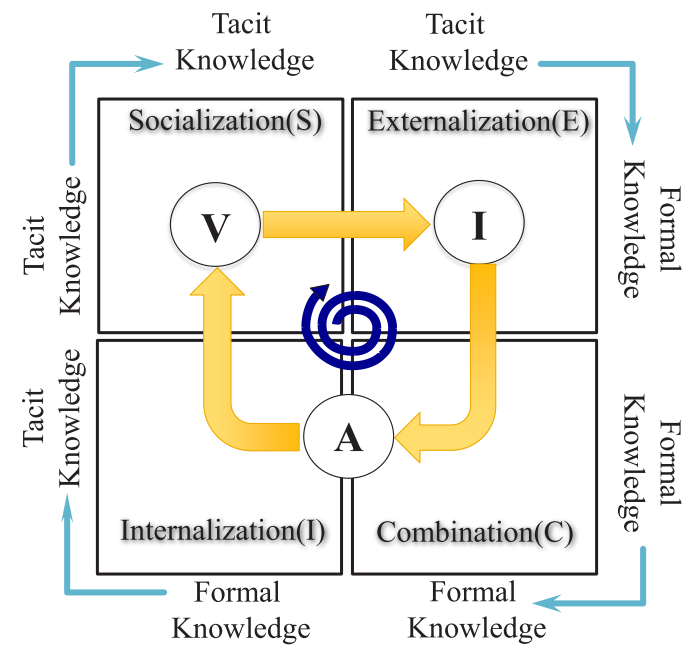

Figure 5: The relationship between VIA and SECI model

Table 1: Comparison of three conceptual framework

\begin{tabular}{|c|c|c|c|}
\hline Concept & $1^{\text {st }}$ Process & $2^{\text {nd }}$ Process & $3^{\text {rd }}$ Process \\
\hline SECI model & Socialization & Externalization & $\begin{array}{c}\text { Combination \& } \\
\text { Internalization }\end{array}$ \\
\hline Sensemaking & Scanning & Interpretation & Enactment \\
\hline VIA Model & V (Values) & I (Intention) & A (Action) \\
\hline
\end{tabular}


Scanning of the Sense-making are equivalent to values recognition of the VIA model. Also, Externalization of the SECI Model and the Interpretation of sense-making are equivalent to foster Intentions of the VIA model. What these three concepts have in common is the identity of subject and object. In Weick's Sense-making, information from the external environment is sensed, the meaning will be made, and acted upon to the external environment.

The starting point of the SECI model is "Socialization," which is the equivalent of "S" in the SECI model. The entrepreneurship education program will explain the concept of "Socialization" with the aim of exploring the potential needs of potential customers during the "Socialization" phase. In developing a new business, the first step is to prepare fieldwork as a means to get a physical sense of what the potential customer needs, by getting inside the potential customer, and to make this tacit knowledge among team members. "Externalization", which corresponds to "E" in the next SECI model, is the phase in which the tacit knowledge shared through "Socialization" is converted into formal knowledge. They formulate a hypothesis based on the needs of potential customers, which they have physically acquired as tacit knowledge through the aforementioned fieldwork, and share among the members as formal knowledge about the things and things that they think potential customers probably want. "Internalization", which corresponds to the last "I" of the SECI model, is the phase in which the linked organizational knowledge is put into practice to produce results and to acquire new tacit knowledge at the individual, team, and organizational levels.

The concept of the SECI model is very different from the aforementioned dualistic educational program of entrepreneurial attitude and practical knowledge/skills, and the SECI model does not think that "entrepreneurial attitude" is the subject and "practical knowledge/skills" is the object. The subject and the object are in an inseparable relationship, and the subject is encompassed by the object, united, mutually working and dependent on it. In other words, instead of having an "entrepreneurial attitude" at the beginning and learning "practical knowledge and skills", we interpret this as a gradual development of an entrepreneurial attitude through the process of learning practical knowledge and skills. The SECI model interprets the transition from the development of entrepreneurial attitudes to practical knowledge and skills not as a parallel transition, but as a sustained cycle of the two complementing each other. There is previous research on cooperative learning in PBL. According to Yuasa et al. [14], the learning

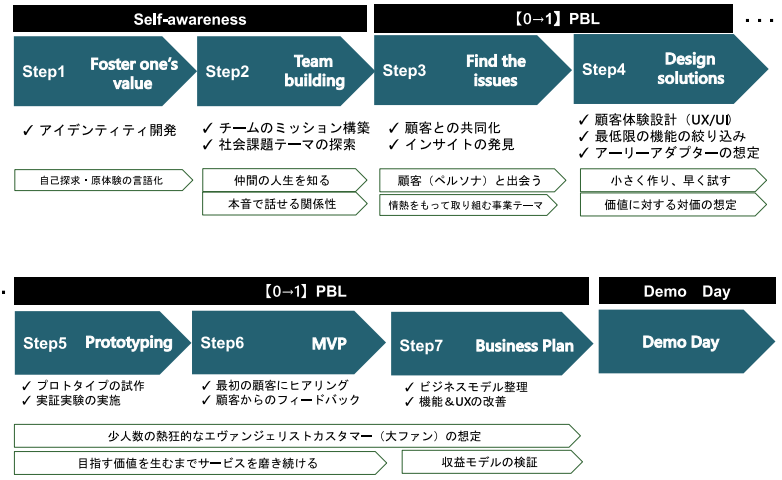

Figure 6: VIA model based PBL process

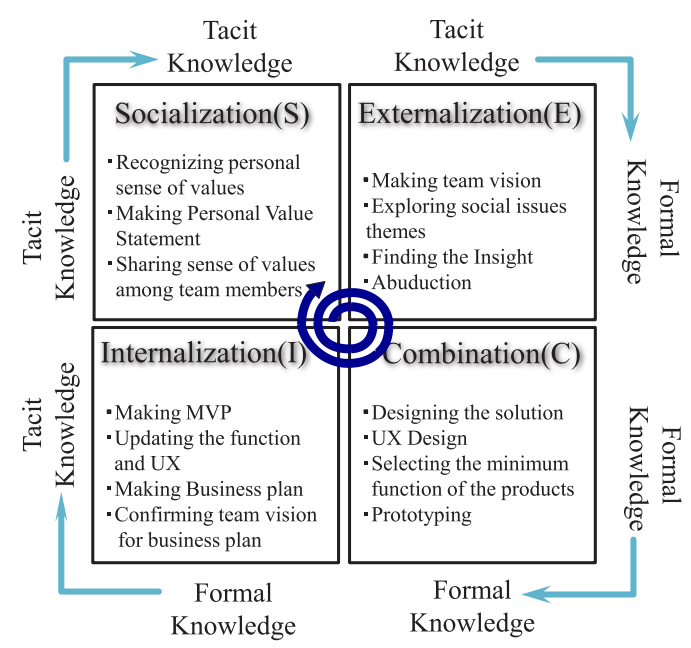

Figure 7: The VIA based PBL process in SECI model

design of PBL is defined as self-directed learning in which students work in groups on highly authentic problems.

According to Okumoto et al. [15], the project members who clarify the purpose of the activity in the early stages of the PBL activity and participate in the necessary decision-making within the team build a cooperative system and build a cooperative system and division of roles. An important point of Okumoto et al.'s study is that the activity autonomy in PBL changes depending on whether or not all of the team members participated in decision-making in the initial activities of PBL. Figure 6 shows VIA model based PBL process. Each process belongs to each quadrant of SECI model as Figure 7 shows.

\section{3. "SOCIALIZATION" PROCESS OF SECI MODEL}

\subsection{Methodologies for self-awareness}

Tasha Eulich [16] states that only $10-15 \%$ of people are confident that they can actually recognize themselves from their own research findings. It means that the most university students do not recognize themselves, perhaps because of their youth. Therefore, in order to activate 
PBL through cooperative learning, it is necessary to utilize some methodologies for recognizing one's own values.

According to Libet [17], what people think they have consciously decided to do is just a subconscious followup. Which means the unconscious mind precedes the conscious mind in decision making. If so, it makes sense to think that some means of self-awareness could be used to evoke an unconscious but already existing the sense of values as "snapshot-like consciousness". It is possible for university and graduate students, who do not have self-awareness, to define the values of their provisional selves by finding words from the value lists that look like current values when they see multiple value lists. In phenomenology, "orientation" means that one's current consciousness is directed toward something and one feels favorable about it, and one confirms the orientation of one's values by extracting values from the unconscious as a "snapshot of consciousness" through the medium of the value card sort.

\subsection{Drawing personal history}

First, each student will work on creating their own history. After drawing the pictures in the four quadrants as Figure 8 shows, the students explain their life history by showing the pictures to the other students. The person listening to the explanation gives feedback to the other person on the personality he or she is feeling while passing notes on a few key words.

\subsection{Personal values card sorting}

University and graduate students are asked to use the Value Card Sort, a list of values, to select several words that relate to the values that they feel are favorable to them at the present time, and while looking at these words, they are asked to reflect on their current values and organize them into sentences.

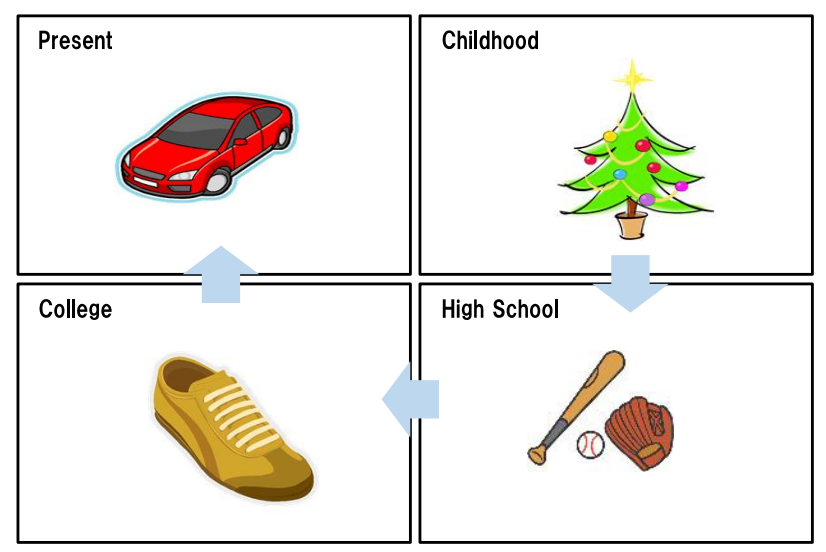

Figure 8: Personal history four quadrant framework
Table 2: The list of "Personal Values Card Sort" plus the seven value words for "Gen Z"

\begin{tabular}{|r|l|r|l|r|l|}
\hline No, & LIST OF VALUES & No, & LIST OF VALUES & No, & LIST OF VALUES \\
\hline 1 & ACCEPTANCE & 31 & GENEROSITY & 61 & POWER \\
\hline 2 & ACCURACY & 32 & GENUINENESS & 62 & PURPOSE \\
\hline 3 & ACHIEVEMENT & 33 & GOD'S WILL & 63 & RATIONALITY \\
\hline 4 & ADVENTURE & 34 & GROWTH & 64 & REALISM \\
\hline 5 & ATTRACTIVENESS & 35 & HEALTH & 65 & RESPONSIBILITY \\
\hline 6 & AUTHORITY & 36 & HELPFULNESS & 66 & RISK \\
\hline 7 & AUTONOMY & 37 & HONESTY & 67 & ROMANCE \\
\hline 8 & BEAUTY & 38 & HOPE & 68 & SAFETY \\
\hline 9 & CARING & 39 & HUMILITY & 69 & SELF-ACCEPTANCE \\
\hline 10 & CHALLENGE & 40 & HUMOR & 70 & SELF-CONTROL \\
\hline 11 & CHANGE & 41 & INDEPENDENCE & 71 & SELF-ESTEEM \\
\hline 12 & COMFORT & 42 & INDUSTRY & 72 & SELF-KNOWLEDGE \\
\hline 13 & COMMITMENT & 43 & INNER PEACE & 73 & SERVICE \\
\hline 14 & COMPASSION & 44 & INTIMACY & 74 & SEXUALITY \\
\hline 15 & CONTRIBUTION & 45 & JUSTICE & 75 & SIMPLICITY \\
\hline 16 & COOPERATION & 46 & KNOWLEDGE & 76 & SOLITUDE \\
\hline 17 & COURTESY & 47 & LEISURE & 77 & SPIRITUALITY \\
\hline 18 & CREATIVITY & 48 & LOVED & 78 & STABILITY \\
\hline 19 & DEPENDABILITY & 49 & LOVING & 79 & TOLERANCE \\
\hline 20 & DUTY & 50 & MASTERY & 80 & TRADITION \\
\hline 21 & ECOLOGY & 51 & MINDFULNESS & 81 & VIRTUE \\
\hline 22 & EXCITEMENT & 52 & MODERATION & 82 & WEALTH \\
\hline 23 & FAITHFULNESS & 53 & MONOGAMY & 83 & WORLD PEACE \\
\hline 24 & FAME & 54 & NON-CONFORMITY & 84 & EMPATHY \\
\hline 25 & FAMILY & 55 & NURTURANCE & 85 & IMPRESSED \\
\hline 26 & FITNESS & 56 & OPENNESS & 86 & LEARNING \\
\hline 27 & FLEXIBILITY & 57 & ORDER & 87 & PERSONALITY \\
\hline 28 & FORGIVENESS & 58 & PASSION & 88 & RELATIONSHIP \\
\hline 29 & FRIENDSHIP & 59 & PLEASURE & 89 & SOCIALCONTRIBUTIONS \\
\hline 30 & FUN & 60 & POPULARITY & 90 & SOLVING SOCIAL ISSUES \\
\hline & & & & \\
\hline
\end{tabular}

Personal Value Card Sorting is a method developed by Miller et al. [18] at the University of New Mexico. There are 83 words about values. The participants of this work were "Generation Z", Japanese university students, and we prepared seven more words: "empathy", "excitement", "learning", "individuality", "connection", "social contribution" and "solving social problems". As Table 2 shows, we have total of 90 words. First, narrow down the number of words that you think are close to your values to 20 , and then narrow it down to 6 of the 20 words. Finally, write a sentence about your values using the six words you chose as a reference.

\subsection{Create personal values statement}

Create a personal statement of values using the student's choice of words as a reference. The following is a sample of the students' value statements in the trial work.

"I like to make things and design things, and I also act on what makes people feel good and moved."

"I like to connect with people and I'm serious about what I want to do."

"I felt with loving companionship, with dreams and hopes, I resolved the negative aspects of society."

\subsection{Share personal values with team members}

Ensure that team members share their own values so that they can mutually understand the other's personalities and subsequently create a vision statement for the team. 


\subsection{Create project team vision statement}

Next, the team members create vision statement for the team before starting PBL. A mission is a definition of what you want to accomplish through your business and its significance to society. A vision is a "vision", meaning the future you want to be.

\section{VERIFICATION AND RESULTS}

\subsection{Results of the personal values card sort}

Figure 9 shows the results of a trial session of Kumamoto University's Innovation Leadership program in which twenty-four university students were asked to classify their own personal values on cards.

"As a result, "fun", "social contribution" and "freedom" were the top three." In addition, "social contribution" is included in the additional seven words of Gen $\mathrm{Z}$. However, due to the limited number of respondents in the current survey, more data would need to be collected in order to read the overall trends.

\subsection{Analysis by questionnaires}

The following five questions will be prepared and asked to fill out a questionnaire after the PBL. University students will be prepared with five questions, as shown in Figure 10. Responses to each question will be evaluated numerically on a 5-point scale.

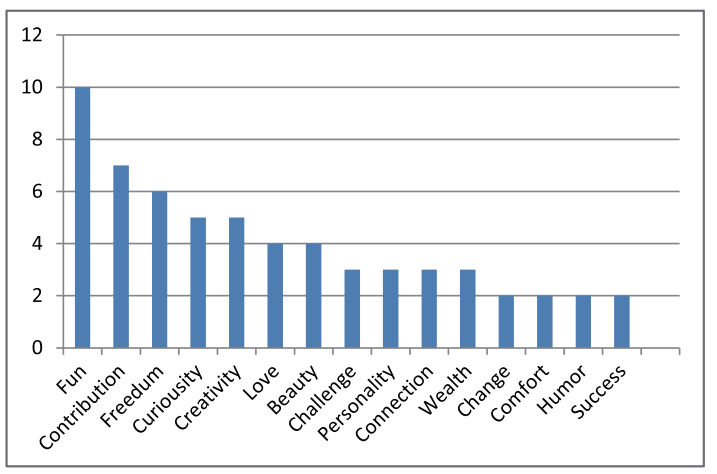

Figure 9: Frequency distribution of value words

\section{The Questionnaires}

Q1: Do you convince of your sense of values?

Q2: Are you satisfied with the results that you participated in PBL?

Q3: Do you think the relationship of your team was good?

Q4: Do you think the team's vision statement has had any impact on the business plan?

Q5: Do you convince of your team's project activities?

Figure 10: Questionnaires after completion of PBL

Table 3: Evaluation score

\begin{tabular}{|ll|}
\hline 1 Point & I do not think so at all \\
2 Points & I do not think so \\
3 Points & I can not say either \\
4 Points & I think so \\
5 Points & I entirely think so \\
\hline
\end{tabular}

After the assessment scores were collected, correlations were determined from the correlation coefficients of each question in order to see the association between the data.

The second question, "Satisfaction with the results of PBL participation," is the overall satisfaction level, as shown in Figure 11.

In this paper, the results of the questionnaires after the completion of PBL were analyzed by two methods: first, the "conviction" of the students who participated in the PBL was focused on, and the correlation coefficients were used to analyze the relationship with the other questions; second, the co-occurrence relationship between words was analyzed by text mining based on the text data of the open-response section of the questionnaires.

In this study, the entrepreneurship education project at Kumamoto University was conducted in PBL format (implementation period: November 2019 - February 2020). seven project teams participated in the PBL, and as Table 4 shows, the number of respondents to the survey was 11 . Two of the seven groups did a series of work from self-awareness to team vision statement in accordance with the VIA model, while the other five groups participated in the self-awareness work but did not participate in the team vision statement creation work due to the mandatory subjects and started PBL activities.

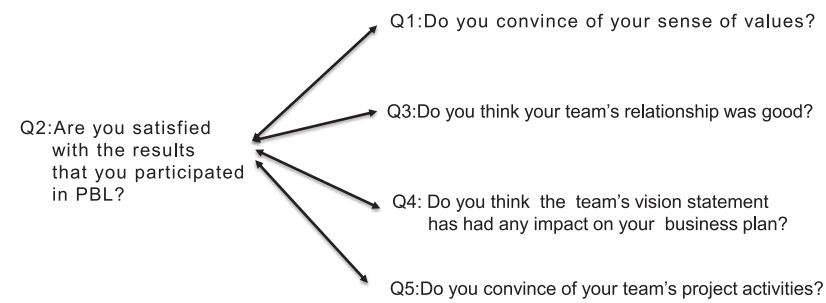

Figure 11: Relevance between Q2 and other questions

Table 4: Questionnaire response data after completion of PBL (5-point evaluation)

\begin{tabular}{|c|c|c|c|c|c|}
\hline Students & $\begin{array}{c}\text { Conviction } \\
\text { for } \\
\text { participating } \\
\text { in PBL }\end{array}$ & $\begin{array}{c}\text { Relationship } \\
\text { with } \\
\text { project } \\
\text { members }\end{array}$ & $\begin{array}{c}\text { Impact of } \\
\text { team vision } \\
\text { on business } \\
\text { plan }\end{array}$ & $\begin{array}{c}\text { Conviction } \\
\text { for team } \\
\text { project } \\
\text { activities }\end{array}$ & $\begin{array}{c}\text { Conviction } \\
\text { of one's } \\
\text { value } \\
\text { perceptions }\end{array}$ \\
\hline A & 2 & 3 & 4 & 3 & 3 \\
\hline B & 4 & 3 & 4 & 2 & 5 \\
\hline C & 2 & 4 & 3 & 3 & 5 \\
\hline D & 3 & 2 & 4 & 2 & 4 \\
\hline E & 5 & 4 & 5 & 3 & 3 \\
\hline F & 5 & 5 & 4 & 4 & 4 \\
\hline G & 5 & 5 & 5 & 5 & 5 \\
\hline H & 5 & 5 & 5 & 5 & 5 \\
\hline I & 5 & 5 & 5 & 5 & 4 \\
\hline J & 5 & 4 & 4 & 5 & 5 \\
\hline K & 4 & 5 & 4 & 4 & 4 \\
\hline Total & 45 & 45 & 47 & 41 & 47 \\
\hline Average & 4.09 & 4.09 & 4.27 & 3.73 & 4.27 \\
\hline
\end{tabular}




\subsection{Analysis by correlation coefficient}

The responses of 11 participants to the five questions presented in Figure 10 were recorded as data and the "correlation coefficient" was used to show the association between the data in objective numbers. Table 5 shows the results of calculating the correlation coefficients from Table 3. Satisfaction with PBL participation is the overall satisfaction level, and the correlation coefficient indicating the strength of the association with the other questions is the shaded part of the table in Table 5.

Looking at the size of the correlation coefficients in Table 6, the questions related to the level of satisfaction with PBL activities were "Relationship with project members (0.620)", "Impact of team vision on business plan (0.725)", and "Satisfaction with team project activities (0.637)". On the other hand, the question that was less related to the level of satisfaction with participation in PBL activities was the level of satisfaction with the perception of one's own values (0.179).

Important to verify the effectiveness of the VIA model as a priming effect was the correlation coefficient between "satisfaction with participation in PBL activities" and "impact of team vision on business plan", which represents overall satisfaction, with a result of 0.725 . In other words, it was shown with statistical significance that the two were quite related. This demonstrates the effectiveness of the "V" process in the VIA model, that is, the priming effect of a series of work that begins with the recognition of one's own values and ends with the creation of team vision statement that positively influences subsequent project activities. The correlation coefficient between "relationship with project members" and "conviction of team project activities" was 0.826 ,

Table 5: Average of the 5-point rating by 11 people

\begin{tabular}{|c|c|c|c|c|}
\hline $\begin{array}{c}\text { Do you } \\
\text { convince of } \\
\text { self-value } \\
\text { perceptions? }\end{array}$ & $\begin{array}{c}\text { Do you } \\
\text { convince of the } \\
\text { results of PBL } \\
\text { participation? }\end{array}$ & $\begin{array}{c}\text { How is the } \\
\text { relationship } \\
\text { with project } \\
\text { team members? }\end{array}$ & $\begin{array}{c}\text { Do you think } \\
\text { team vision } \\
\text { statement affect } \\
\text { anything to your } \\
\text { business plan? }\end{array}$ & $\begin{array}{c}\text { Do you } \\
\text { convince of } \\
\text { your project } \\
\text { team activities } \\
\text { through PBL? }\end{array}$ \\
\hline 4.27 & 4.09 & 4.09 & 4.27 & 3.73 \\
\hline
\end{tabular}

indicating that the team members' mutual understanding and respect for each other's "personalities" and maintaining good human relationships through the work of "Socialization" within the team had a great deal to do with conviction of project activities.

\subsection{Analysis by co-occurrence network}

We utilized KH Coder, an open-source software for text mining, to analyze the co-occurrence relationships in the text data written on the questionnaires we collected. The co-occurrence relationship was analyzed by using co-occurrence network that visually represents the strongly connected words by connecting them with a straight line. In the co-occurrence network, we applied the Jaccard coefficient as a measure of the strength of the co-occurrence relationship, which is numerical value to express the co-occurrence relationship probabilistically.

Figure 12 shows the co-occurrence network created from the text data of the questionnaires obtained from the five teams. These five teams participated in the Self-Awareness workshop, but due to the mandatory subjects with their course work, they did not do the work of creating team vision statement and started the project activities. Therefore, the VIA model is not being utilized.

In this co-occurrence network, there is no straight line showing the co-occurrence relationship between each cluster.

Although the word "team" was present, there were no words that indicated a relationship with team members or a relationship with self-awareness, and there were no particular elements that indicated the effectiveness of cooperative learning. Figure 13 shows the co-occurrence network created based on the text data of the questionnaires of two teams with total of six participants.

Following the VIA model, these two teams embarked on a series of work, from recognizing their own values to creating their team vision statement, to developing their business plan. In this co-occurrence network, a dotted line can be seen showing the co-occurrence relationship between each cluster.

Table 6: Correlation coefficient

\begin{tabular}{|l|c|c|c|c|c|}
\hline \multicolumn{1}{|c|}{ Questionnaires } & $\begin{array}{c}\text { Convinced of } \\
\text { participating in } \\
\text { this PBL program }\end{array}$ & $\begin{array}{c}\text { Convinced of } \\
\text { recognizing my } \\
\text { own sense of values }\end{array}$ & $\begin{array}{c}\text { Relationship } \\
\text { with project } \\
\text { members }\end{array}$ & $\begin{array}{c}\text { Influence of } \\
\text { team vision to } \\
\text { business plan }\end{array}$ & $\begin{array}{c}\text { Convinced } \\
\text { of the project } \\
\text { activities }\end{array}$ \\
\hline Q1: Convinced of participating in this PBL program & 1 & 0.179 & 0.620 & 0.725 & 0.637 \\
\hline Q2: Convinced of recognizing my own sense of values & 0.179 & 1 & 0.210 & -0.160 & 0.300 \\
\hline Q3: Relationship with project members & 0.620 & 0.210 & 1 & 0.403 & 0.826 \\
\hline Q4: Influence of team vision to business plan & 0.725 & -0.160 & 0.403 & 1 & 0.495 \\
\hline Q5: Convinced of the project activities & 0.637 & 0.300 & 0.826 & 0.495 & 1 \\
\hline
\end{tabular}




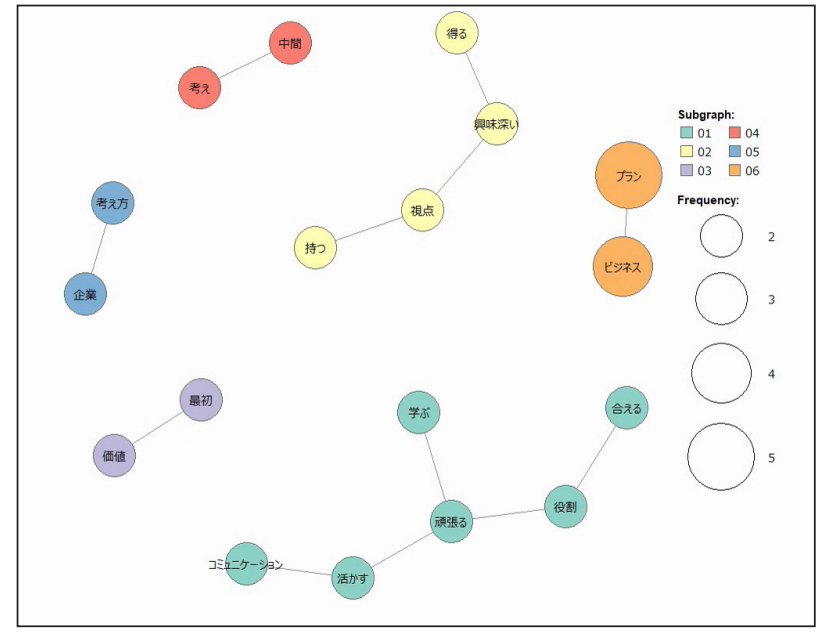

Figure 12: Co-occurrence networks of project teams that did not use the VIA model

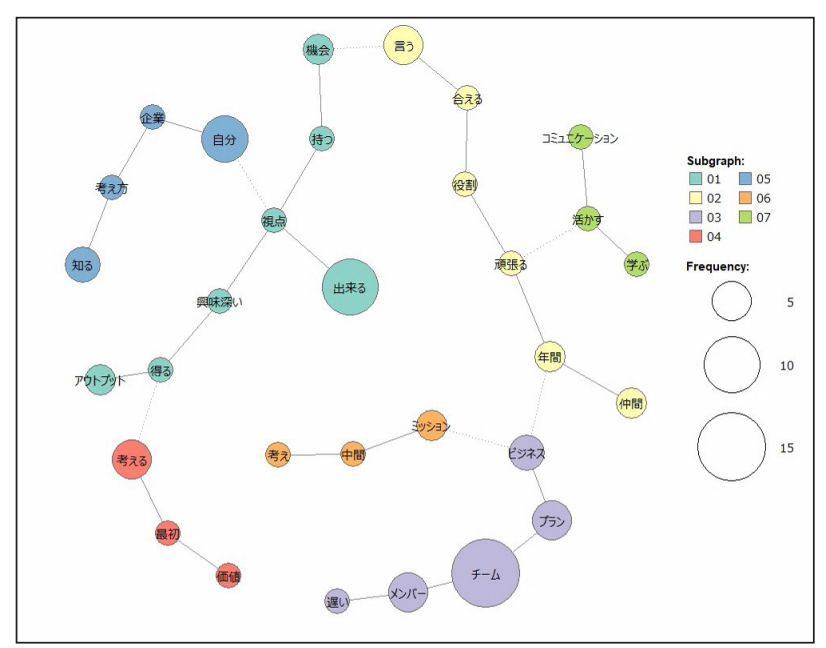

Figure 13: Co-occurrence network of project teams that used the VIA model

In addition, there were many nouns such as "team," "peers," "mission," "myself," "can do," and "think," which indicating the effectiveness of cooperative learning, as the students were aware of teamwork with team members based on their own self-awareness through the project activities. These two co-occurrence networks illustrate the effectiveness of the VIA model in PBL activities.

\section{CONCLUSION}

Fostering the entrepreneurial intentions is quite difficult in entrepreneurship education programs. We defined the motivation to complete the PBL activities as the preliminary stage of the entrepreneurial intentions, and developed the VIA Model as a specific methodology for this purpose.

The rationale for these initiatives rely on the results of Libet's experiments and Husserl's phenomenology.
According to Libet, the unconscious precedes the conscious mind. Also, Tomano states that it is undeniable to think that this is what I recognize my sense of values at the moment with the nature of Husserl's phenomenology.

Therefore, it is possible to question university students about their "snapshot-like" tentative sense of values. And we verified the hypothesis that self-awareness would have a positive impact on subsequent PBL activities.

This paper examines the effectiveness of the VIA model in entrepreneurship education program in terms of the priming effect on subsequent PBL activities. In addition, although conviction of self-awareness does not directly affect conviction of participation in PBL activities, we were able to verify the effectiveness of the team members' self-awareness of values as a starting point for a series of "Socialization" processes, from understanding each other's "personalities" to creating a team vision statement.

Although we were able to develop the VIA model through this study, there are future issues such as improving the usability of the PBL activity process and collaborative learning based on the SECI model, and collecting more participant data.

\section{ACKNOWLEDGEMENTS}

This study was partly supported by Innovation Leadership Program in Kumamoto University.

\section{REFERENCES}

1. Kwong, C., and Thompson, P.; The when and why: Student entrepreneurial aspirations, Journal of Small Business Management, 54(1), pp.299-318, 2016.

2. Takahashi, N.; Spectrum of Entrepreneurship education program, Business Creator Research, Rikkyo University, pp.97-112, 2014. (in Japanese)

3. Nonaka, I., and Takeuchi, H.; The knowledge creating company, Oxford University Press, pp.83109, pp.188-194, 1996.

4. Ajzen, I.; The theory of planned behavior, Organizational Behavior and Human Decision Processes, 50(2), pp.179-211, 1991.

5. Krueger, N.F., and Day, M., Chapter 13 Looking forward, looking backward: From entrepreneurial cognition to neuroentrepreneurship, Handbook of Entrepreneurship Research, pp.321-332, 2011.

6. Simon, H.A.; The science of the artificial, MIT Press, Cambridge, MA, 1969.

7. Sinek, S.; Start with why, Nihonkeizaishinbun shuppansha, Japan, p.79, 2012. 
8. March, J. G., Olsen, J.P., and Christensen, S.; Ambiguity and choice in organization, Universitestforlaget, Oslo, Norway, 1976.

9. Weick, K.W.; The social psychology of organizing, Addison Wesley, MA, 1979.

10. Tomano, I.; Hajimeteno Tetsugakutekishikou (My first philosophical thought), Chikuma-premershinsho, Japan, pp103-108, 2017. (in Japanese)

11. Nabi, G., Fayolle, A., Krueger, N., and Walmsley, A.; The impact of entrepreneurship education in higher education: Systematic review and research agenda, Academy of Management Learning \& Education, 16(2), pp.277-299, 2017.

12. Kahneman, D.; Thinking, fast and slow, Hayakawa Publishing, Japan, pp.97-108, 2014.

13. Iriyama, A.; Management theories of the global standard, Diamond Publishing, Japan, pp.269-282, 2019. (in Japanese)

14. Yuasa, K., Oshima, J., Oshima, R., Characteristics and effectiveness of PBLs: Problem-based learning \& project-based learning, Shizuoka University, Departmental Bulletin Paper, 16, pp.15-22, 2011.

15. Okumoto, M.; Spontaneous action analysis on PBL, Japan Society for Educational Technology, 36(3), pp.205-215, 2012. (in Japanese)

16. Eurich, T.; What self-awareness really is (and how to cultivate it), Harvard Business Review, NY, pp.1-2, 2018.
17. Libet, B.; Mind time - The temporal factor in consciousness, Iwanami Shoten, Japan, pp.39-103, 2005. (in Japanese)

18. Miller, W.R., C'de Baca, J., Matthews, D.B., and Wilbourne, P.L.; Personal values card sort, University of New Mexico, Albuquerque, 2001.

19. Takahashi, K., and Kiyosumi, M.; Proposal of the VIA model for PBL activation with recognizing "Snapshot-like" intuitive sense of values, Proceeding of the 6th International Symposium on Affective Science and Engineering, 2020.

Koichi TAKAHASHI (Member)

Koichi Takahashi is a Doctoral student, 2nd year, Department of Kansei Science, Graduate School of Integrated Frontier Science Kyushu University, Japan. He is currently member of JSKE. His interests are Kansei engineering, Educational engineering and Entrepreneurship Education. He is a professor of Kumamoto Innovative Development Organization in Kumamoto University.

e-mail: takahashi.koichi.538@s.kyushu-u.ac.jp

\section{Masahiro KIYOSUMI (Member)}

Masahiro Kiyosumi is a Professor of Department of Kansei Science, Graduate School of Integrated Frontier Science, Kyushu University, Japan. He is Takahashi's doctoral thesis advisor. 